\title{
Improving sensitivity of residual current transformers to high frequency earth fault currents
}

\author{
STANISLAW CZAPP, KRZYSZTOF DOBRZYNSKI, JACEK KLUCZNIK, \\ ZBIGNIEW LUBOSNY, ROBERT KOWALAK \\ Faculty of Electrical and Control Engineering, Gdańsk University of Technology \\ Narutowicza 11/12, 80-233 Gdańsk, Poland \\ e-mail: stanislaw.czapp@pg.gda.pl
}

(Received: 20.09.2016, revised: 20.02.2017)

\begin{abstract}
For protection against electric shock in low voltage systems residual current devices are commonly used. However, their proper operation can be interfered when high frequency earth fault current occurs. Serious hazard of electrocution exists then. In order to detect such a current, it is necessary to modify parameters of residual current devices, especially the operating point of their current transformer. The authors proposed the modification in the structure of residual current devices. This modification improves sensitivity of residual current devices when high frequency earth fault current occurs. The test of the modified residual current device proved that the authors' proposition is appropriate.
\end{abstract}

Key words: current transformers, earth fault currents, electric devices, electromagnetic couplings, high frequency

\section{Introduction}

Protection against electric shock in low voltage systems, according to the standard [1], is very often realized with the use of residual current devices (RCDs). They are applied in various types of electrical circuits, also in circuits where earth fault current with high frequency components or high peak value transient leakage current flows. It leads to the problem of RCDs compatibility with such types of current. This problem is discussed in many papers [2-10]. Voltage and current harmonics are mainly produced by power electronics converters [2].

An example oscillogram of the earth fault current from a circuit with a frequency converter is presented in Fig. 1. The waveform in Fig. 1 comprises harmonics, especially high-order harmonics. The order of harmonics corresponds with the applied PWM frequency of the converter.

Typical residual current devices are not compatible with the detection of high frequency sinusoidal residual currents and residual currents with harmonics. For such earth fault currents, the tripping current of residual current devices can be very high [2]. 


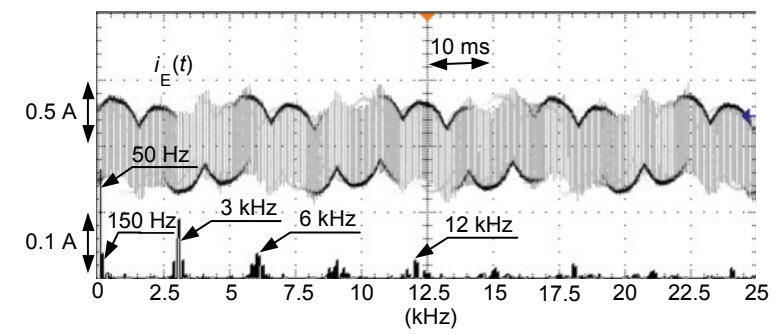

Fig. 1. Oscillogram of earth fault current $(0.5 \mathrm{~A} / \mathrm{div})$ in the case of fault in the output terminals of the frequency converter and spectrum of this current $(0.1 \mathrm{~A} / \mathrm{div})$

This negatively influences the effectiveness of protection against electric shock. Fig. 2 presents the tripping current of the example RCDs as a function of earth fault (residual) current frequency. The tripping current of these RCDs rises with frequency rising, but their sensitivity to current frequency is not the same. RCD2 is sensitive to the whole testing frequency range. In the case of RCD1 there is no tripping if frequency exceeds $400 \mathrm{~Hz}$. The tripping current is very important especially for residual current devices of $I_{\Delta \mathrm{n}}=30 \mathrm{~mA}$ rated residual current. If the tripping current rises strongly with frequency rising, the threshold of ventricular fibrillation may be exceeded and real hazard of electrocution exists. Such dangerous behaviour is represented by the tested RCD1 (Fig. 2). Its tripping current does not exceed the threshold of ventricular fibrillation only for frequencies not higher than $300 \mathrm{~Hz}$.

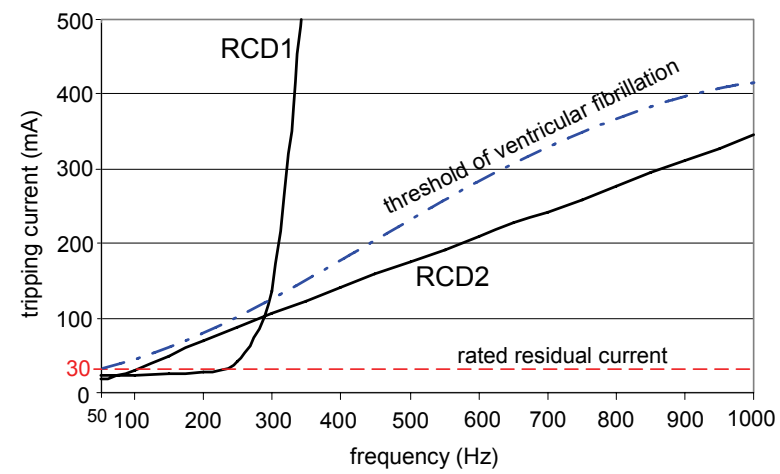

Fig. 2. Tripping current of the selected residual current devices (RCD1 and RCD2, $I_{\Delta \mathrm{n}}=30 \mathrm{~mA}$ ) as a function of earth fault current frequency

Moreover, commonly used residual current devices (AC-type and A-type according to [11]) are not verified by their manufactures under high frequency conditions, because the international standard [11] delivering general requirements for residual current devices, does not require such verification. Thus, it is important to perform analysis of the behaviour of main components of residual current devices, especially their current transformer, when high frequency residual current flows. 


\section{Analysis of the operation of the residual current transformer}

A residual current device comprises an iron core current transformer (CT) and an electromechanical relay (ER) with a permanent magnet (Fig. 3). The secondary current $i_{\mathrm{s}}(t)$, transformed by the current transformer, in the one half-wave amplifies the magnetic flux of the permanent magnet but in the second half-wave that flux is reduced. If the current $i_{\mathrm{s}}(t)$ reaches a predetermined level, the magnetic flux derived from that current is high enough to reduce the magnetic flux of the permanent magnet, and RCD opens the main circuit. In order to ensure sufficient value of secondary current $i_{\mathrm{s}}(t)$, sufficient value of secondary voltage $e_{\mathrm{s}}(t)$, especially peak value, should be induced.

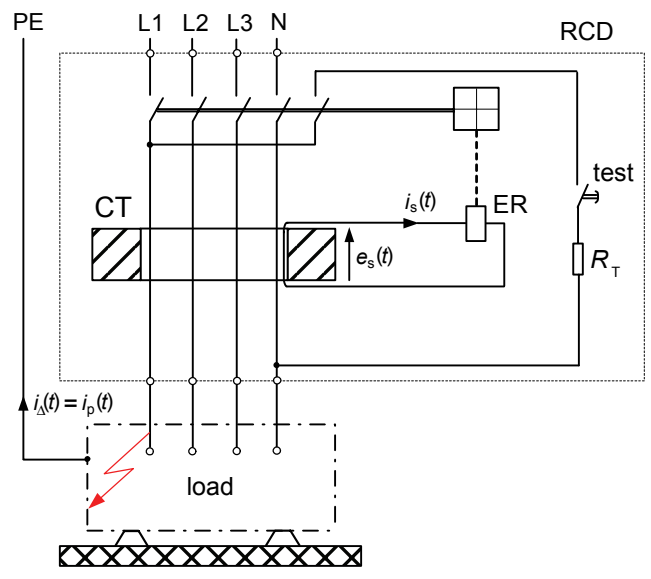

Fig. 3. Simplified diagram of a residual current device (RCD): CT - current transformer, ER electromechanical relay, $R_{\mathrm{T}}$ - test resistance, $i_{\Delta}(t)$ - residual (earth fault) current, $i_{\mathrm{p}}(t)-$ primary current of the current transformer, $i_{\mathrm{s}}(t)-$ secondary current of the current transformer, $e_{\mathrm{s}}(t)$ - induced secondary voltage of the current transformer

Secondary voltage (rms value) is defined by the following formula:

$$
E_{\mathrm{s}}=4.44 \cdot f \cdot N_{\mathrm{s}} \cdot \Phi=4.44 \cdot f \cdot N_{\mathrm{s}} \cdot B \cdot s_{\mathrm{Fe}},
$$

where: $f$ is the earth fault current frequency, $N_{\mathrm{s}}$ is the number of turns of the secondary winding, $\Phi$ is the magnetic field strength, $B$ is the magnetic induction, $s_{\mathrm{Fe}}$ is the current transformer core cross-section.

Unfortunately, in some cases this voltage does not rise proportionally to frequency (Fig. 4). For a primary current equal to the rated residual current $I_{\Delta \mathrm{n}}$ of a RCD, the induced voltage $e_{\mathrm{s}}(t)$ rises only slightly. If frequency rises 20 times (from 50 to $1000 \mathrm{~Hz}$ ) the peak value of $e_{\mathrm{s}}(t)$ rises about 1.35 times (instead of 20). It means that the tripping threshold of a residual current device rapidly rises and protection against electric shock may not be effective.

Fig. 5 presents peak values of the induced secondary voltage $e_{\text {peak }}$ as a function of frequency. These values are presented in relation to the value of a frequency equal to $50 \mathrm{~Hz}$. One can see that for frequencies higher than $250 \mathrm{~Hz}$ the peak value of induced voltage is almost constant. 


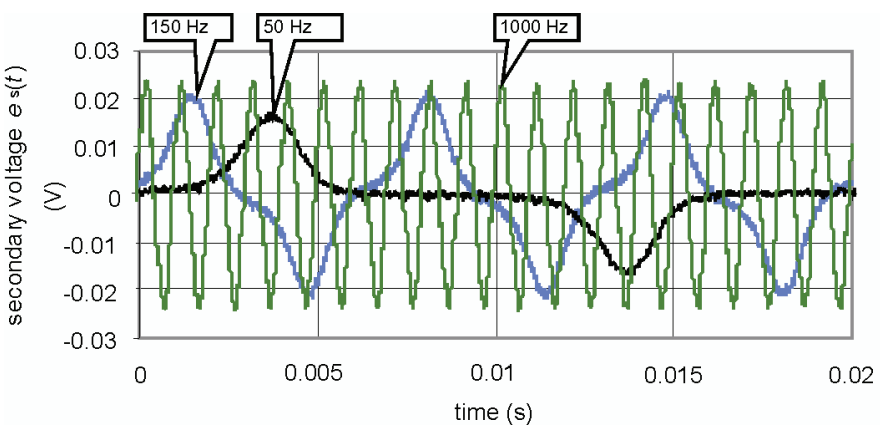

Fig. 4. Measured (for an example residual current device) secondary voltage $e_{\mathrm{s}}(t)$ for primary current $i_{\mathrm{p}}(t)$ equal to the rated residual current $I_{\Delta \mathrm{n}}$; frequency: $50,150,1000 \mathrm{~Hz}$

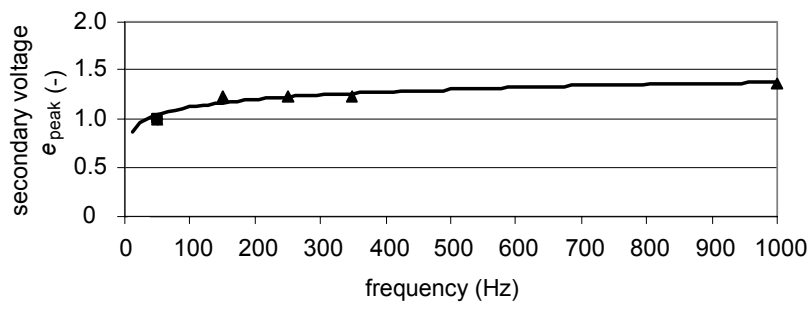

Fig. 5. Secondary voltage $e_{\text {peak }}$ (peak value in relation to the reference value of $50 \mathrm{~Hz}$ ) of the current transformer for the frequency range $50-1000 \mathrm{~Hz}$ for primary current $I_{\Delta \mathrm{n}} ;\left(I_{\Delta \mathrm{n}}\right.$ is a rated residual current of the RCD)

One of the main cause of the results presented in Fig. 4 and Fig. 5 is a very wide hysteresis loop of the iron core of the current transformer for high frequency (Fig. 6). The hysteresis loop shapes can be various [12-16] and may have a crucial impact on the sensitivity of the current transformer to the earth current waveform. To achieve the same level of induction in the current transformer core, for higher frequencies, a higher value of earth fault current is necessary.

In the case of this iron core, the proper operation of a residual current device (for various frequencies) can be achieved when the operating point of a current transformer (i.e. iron core) is situated close to the saturation point for the highest expected frequency (for example fs 1000 if the highest frequency is equal to $1000 \mathrm{~Hz}$ ).

The designing process of the residual current devices for circuits of a high frequency residual current should take into account the properties of the iron core of a residual current transformer in the presence of high frequency waveforms. The operating point of the current transformers should then be modified. Fig. 7 presents induced secondary voltage obtained for the proposed modified operating point of the current transformer. The expected rise in voltage occurs for a primary current equal to $5 I_{\Delta \mathrm{n}}$. It is observed that the most important value of the induced secondary voltage - peak value - significantly rises with frequency rising (positive effect). This result may be achieved by modification of the windings. The simplest solution is to change the number of turns of the primary winding. 


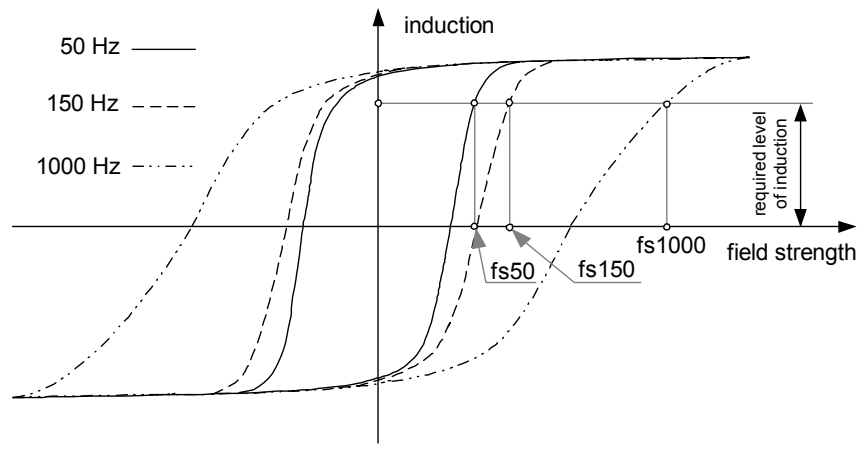

Fig. 6. Hysteresis loops of the selected current transformer for various frequency primary current. Required magnetic field strength: fs 50 for $50 \mathrm{~Hz}$, fs 150 for $150 \mathrm{~Hz}$, fs 1000 for $1000 \mathrm{~Hz}$

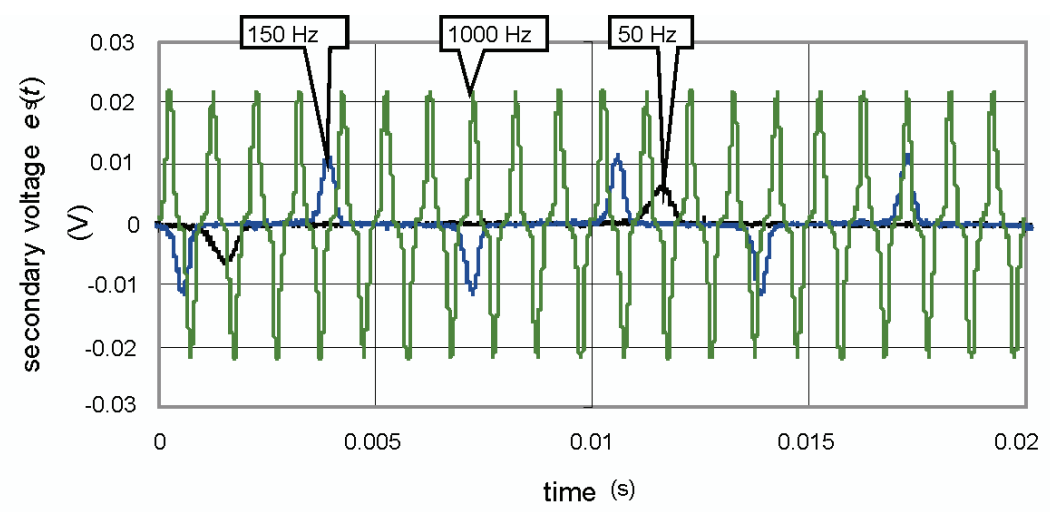

Fig. 7. Measured (for example residual current device) secondary voltage $e_{\mathrm{s}}(t)$ for primary current $i_{\mathrm{p}}(t)$ equal to the residual current $5 I_{\Delta \mathrm{n}}$; frequency: $50,150,1000 \mathrm{~Hz}$

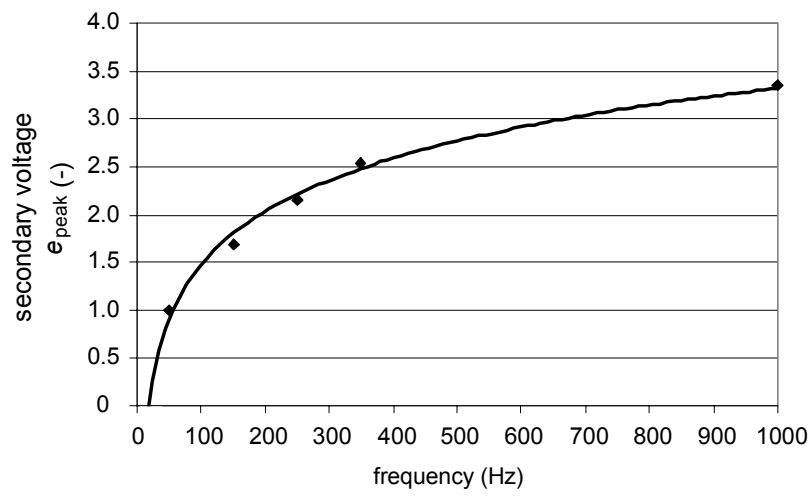

Fig. 8. Secondary voltage $e_{\text {peak }}$ (peak value in relation to the reference value of $50 \mathrm{~Hz}$ ) of the current transformer for the frequency range $50-1000 \mathrm{~Hz}$ for primary current $5 I_{\Delta \mathrm{n}}\left(I_{\Delta \mathrm{n}}\right.$ is a rated residual current of the RCD) 
The secondary voltage $e_{\text {peak }}$ (peak value in relation to a reference value of $50 \mathrm{~Hz}$ ) of the current transformers for the frequency range $50-1000 \mathrm{~Hz}$, for the primary current $5 I_{\Delta \mathrm{n}}$, is presented in Fig. 8. Comparing Fig. 8 to Fig. 5 one can see that the increase of the peak value is more favourable for $5 I_{\Delta \mathrm{n}}$ (Fig. 8) than for $I_{\Delta \mathrm{n}}$ (Fig. 5).

\section{Properties of a modified current transformer for high frequency RCDs}

Taking into account the above mentioned properties of residual current transformers for the detection of high frequency primary current waveforms, a laboratory model of a residual current transformer has been designed. In this concept the current transformer is dedicated for a RCD of $I_{\Delta \mathrm{n}}=300 \mathrm{~mA}$ and its real tripping current should be within $0.5 I_{\Delta \mathrm{n}}-I_{\Delta \mathrm{n}}(150-300 \mathrm{~mA})$ for the frequency range $50-1000 \mathrm{~Hz}$. An equivalent circuit of a residual current device is presented in Fig. 9.

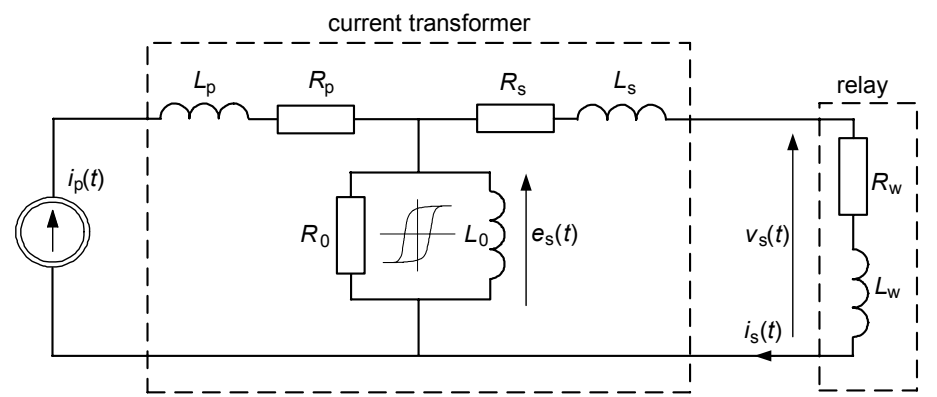

Fig. 9. Equivalent circuit of a residual current device; $i_{\mathrm{p}}(t)$ - primary current of the current transformer, $i_{\mathrm{s}}(t)$ - secondary current of the current transformer, $e_{\mathrm{s}}(t)$ - induced secondary voltage of the current transformer, $v_{\mathrm{s}}(t)$ - electromechanical relay voltage; core of the current transformer modeled as a non-linear system

The induced secondary voltage of the laboratory model of the current transformer was measured. The model was prepared and tested for primary current equal to $220 \mathrm{~mA}$ - it is close to the geometric mean value of the range of $150-300 \mathrm{~mA}$. The results of the test are presented in Fig. 10.

Fig. 11, in turn, presents the peak values of the secondary voltage in relation to a reference value of $50 \mathrm{~Hz}$, for easy comparison with the values presented in Fig. 5 and Fig. 8. In this case (Fig. 11) the rise of the secondary voltage is even higher than in Fig. 8. It is favorable behaviour of the current transformer.

An electromechanical relay was connected to the secondary circuit of such designed residual current transformer. According to the above presented assumption, this arrangement should be able to trip within $150-300 \mathrm{~mA}$ for the frequency range $50-1000 \mathrm{~Hz}$. A tripping characteristic of this arrangement is presented in Fig. 12. Permissible values of the tripping current are marked as a shaded area. 
The tripping current of the laboratory model of the RCD is within the permissible range only for frequencies $50-500 \mathrm{~Hz}$, in spite of the favorable rise of the induced secondary voltage (Fig. 11). The cause of too high values of the tripping current within the frequency range $500-1000 \mathrm{~Hz}$ lies in the construction of the electromechanical relay. The electromechanical relay usually comprises a permanent magnet and a coil.

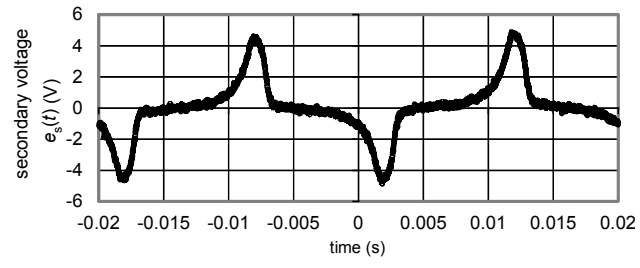

(a)

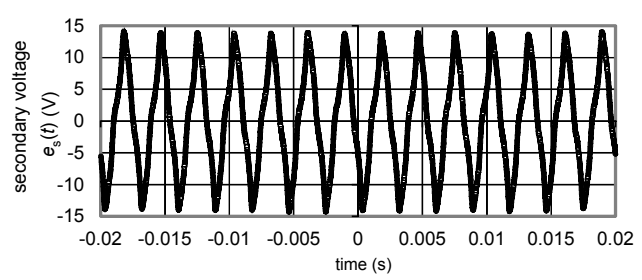

(c)

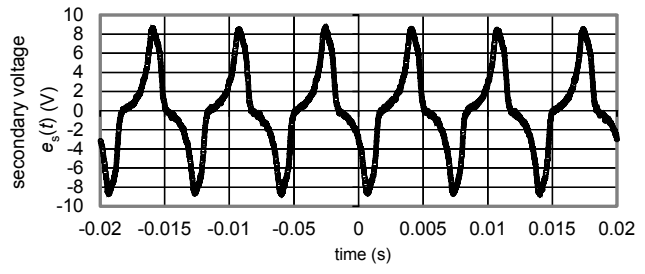

(b)

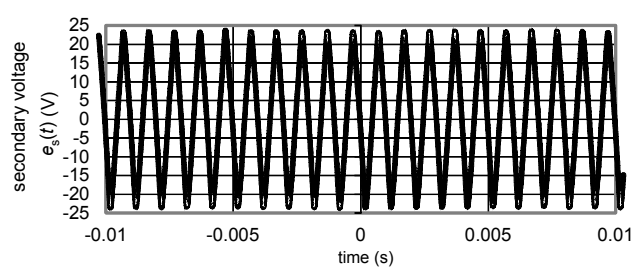

(d)

Fig. 10. Waveforms of induced secondary voltage $e_{\mathrm{s}}(t)$ of the proposed residual current transformer with an operating point adapted to frequency range $50-1000 \mathrm{~Hz}$. Frequency of primary current: a) $50 \mathrm{~Hz}$; b) $150 \mathrm{~Hz}$;) $350 \mathrm{~Hz}$;) $1000 \mathrm{~Hz}$

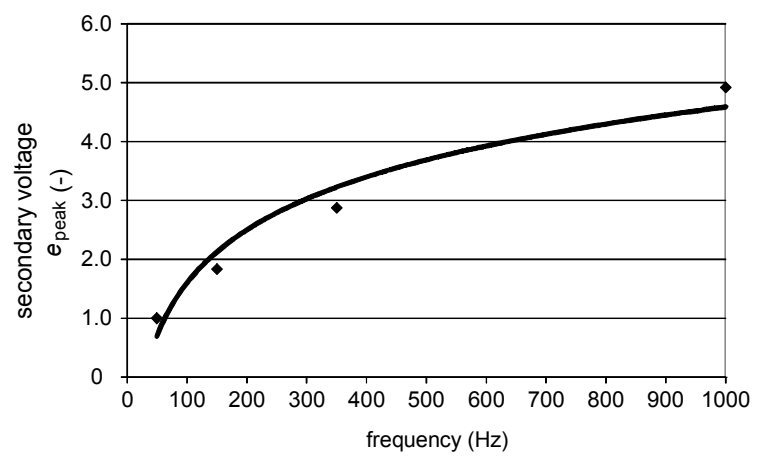

Fig. 11. Secondary voltage $e_{\text {peak }}$ (peak value in relation to the reference value of $50 \mathrm{~Hz}$ ) of the current transformer of the proposed RCD $300 \mathrm{~mA}$ for the frequency range $50-1000 \mathrm{~Hz}$; primary current $220 \mathrm{~mA}$

The equivalent circuit of the electromechanical relay is represented by the resistance $R_{\mathrm{w}}$ and reactance $X_{\mathrm{w}}\left(L_{\mathrm{w}}\right)$ as it is shown in Fig. 9. The high frequency residual (primary) current of the current transformer and the induced secondary voltage derived from this primary cur- 
rent produce a high frequency secondary current. The higher the frequency of the secondary current the higher the impedance of the electromechanical relay. In order to avoid the effect of a high frequency waveform on electromechanical relay, an $\mathrm{AC} / \mathrm{DC}$ converter in the secondary circuit of the current transformer may be used (Fig. 13) [17].

After the application of the mentioned $\mathrm{AC} / \mathrm{DC}$ converter, a tripping characteristic of the arrangement was checked again (Fig. 14). In this case the characteristic is favorable for the whole tested frequency range $(50-1000 \mathrm{~Hz})$.

Sensitivity of residual current devices is determined, among others, by the frequency-response of both the current transformer and the electromechanical relay. With the AC/DC converter, the relay responds to the DC current only, no matter what frequency (harmonics) the primary (also secondary) current has. In general, the $\mathrm{AC} / \mathrm{DC}$ converter is frequency-independent.

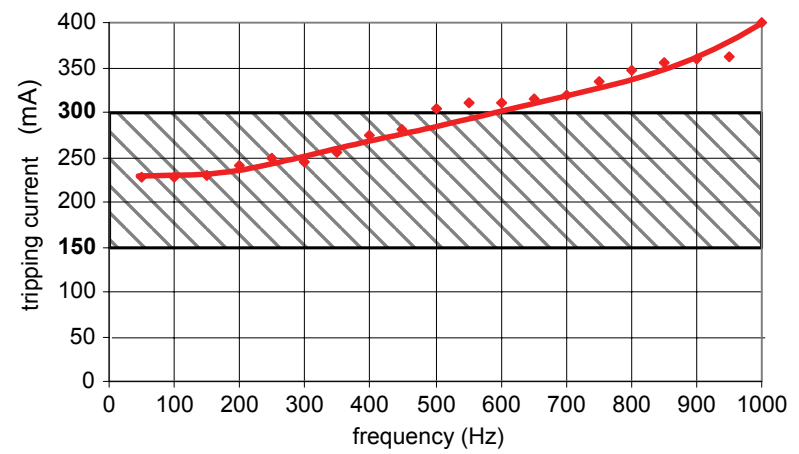

Fig. 12. Tripping current of the tested laboratory model of $300 \mathrm{~mA} \mathrm{RCD}$ shaded area - permissible values of tripping current
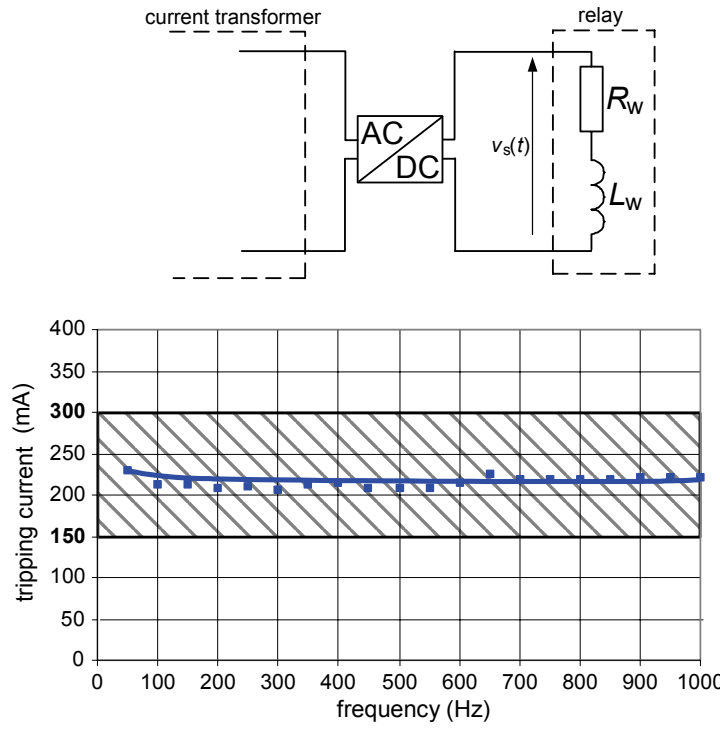

Fig. 13. Application of an AC/DC converter in the secondary circuit of the current transformer, $v_{\mathrm{s}}(t)$ - electromechanical relay voltage (here - DC voltage)

Fig. 14. Tripping current of the tested laboratory model of $300 \mathrm{~mA}$ RCD when an $\mathrm{AC} / \mathrm{DC}$ converter in the secondary circuit is applied; shaded area - permissible values of tripping current 


\section{Conclusions}

Most of commonly used residual current devices do not detect a high frequency earth fault current properly. The reliable operation of RCDs for such a current strictly depends on the properties of the residual current transformer applied in the RCDs. The process of selection of this transformer and its coordination with other elements of RCDs should take into account the frequency range of the earth fault current to be detected. The above proposed modifications of the residual current transformer improves operation of residual current devices when a high frequency earth fault current flows.

\section{References}

[1] HD 60364-4-41, Low-voltage electrical installations - Part 4-41: Protection for safety - Protection against electric shock (2007).

[2] Czapp S., The effect of earth fault current harmonics on tripping of residual current devices, Proceedings of the International School on Nonsinusoidal Currents and Compensation, IX Conference-Seminar ISNCC 2008, Lagow, Poland (2008), DOI: 10.1109/ISNCC.2008.4627489.

[3] Czapp S., Comparison of residual current devices tripping characteristics for selected residual current waveforms, Elektronika ir Elektrotechnika, vol. 100, no. 4, pp. 7-10 (2010).

[4] Czapp S., Borowski K., Immunity of residual current devices to the impulse leakage current in circuits with variable speed drives, Elektronika ir Elektrotechnika, vol. 19, no. 8, pp. 15-18 (2013), DOI: 10.5755/j01.eee.19.8.2883.

[5] Donahue, S.T., Storm C.L., Wetz Jr. D.A., Lee W.-J., Study of the effects of smart meter RF transmissions on GFCI outlets, IEEE Transactions on Electromagnetic Compatibility, vol. 56, no. 6, pp. 1361-1369 (2014), DOI: 10.1109/TEMC.2014.2354016.

[6] Freschi F., High-frequency behavior of residual current devices, IEEE Transactions on Power Delivery, vol. 27, no. 3, pp. 1629-1635 (2012), DOI: 10.1109/TPWRD.2012.2191423.

[7] Lee T.M., Chan T.W., The effects of harmonics on the operational characteristics of residual current circuit breakers, International Conference on Energy Management and Power Delivery, Proceedings of EMPD'95, pp. 715-719 (1995), DOI: 10.1109/EMPD.1995.500786.

[8] Luo X., Du Y., Wang X.H., Chen M.L., Tripping characteristics of residual current devices under nonsinusoidal currents, IEEE Transactions on Industry Applications, vol. 47, no. 3, pp. 1515-1521 (2011), DOI: 10.1109/TIA.2011.2125939.

[9] Roldan-Porta C., Escriva-Escriva G., Cárcel-Carrasco F.J., Roldan-Blay C., Nuisance tripping of residual current circuit breakers: A practical case, Electric Power Systems Research, vol. 106, pp. 180-187 (2014), DOI: 10.1016/j.epsr.2013.07.020.

[10] Schoneck J., Nebon Y., LV protection devices and variable speed drives, Cahier technique No. 204, Schneider Electric (2002).

[11] IEC/TR 60755, General requirements for residual current operated protective devices. 2nd edition (2008).

[12] Chwastek K., Szczygłowski J., The effect of anisotropy in the modified Jiles-Atherton model of static hysteresis, Archives of Electrical Engineering, vol. 60, no. 1, pp. $49-57$ (2011), DOI: 10.2478/v10171-011-0005-8.

[13] Colin B., Kedous-Lebouc A., Chillet C., Mas P., Wound magnetic core consequences on false residual currents, COMPEL: The International Journal for Computation and Mathematics in Electrical and Electronic Engineering, vol. 27, iss. 1, pp. 246-255 (2008), DOI: 10.1108/ 03321640810836807.

[14] Ladjimi A., Mékideche M., Babouri A., Thermal effects on magnetic hysteresis modelling, Archives of Electrical Engineering, vol. 61, no. 1, pp. 77-84 (2012), DOI: 10.2478/v10171-012-0007-1. 
[15] Naghizadeh R.A., Vahidi B., Hosseinian S.H., Calculation of inrush current using adopted parameters of the hysteresis loop, COMPEL: The International Journal for Computation and Mathematics in Electrical and Electronic Engineering, vol. 33, iss. 5, pp. 1794-1808 (2014), DOI: 10.1108/COMPEL-08-2012-0133.

[16] Nová I., Havlíček V., Zenek I., Dynamic hysteresis loops modeling by means of extended hyperbolic model, IEEE Transactions on Magnetics, vol. 49, no. 1, pp. 148-151 (2013), DOI: 10.1109/ TMAG.2012.2218584.

[17] Czapp S., Elimination of the negative effect of earth fault current higher frequency on tripping of residual current devices, Elektronika ir Elektrotechnika, vol. 91, no. 3, pp. 85-88 (2009). 